\title{
The Transforming Face of Fracture Epidemiology: Our Concern
}

\author{
Hayat Ahmad Khan ${ }^{1, *}$ \\ ${ }^{1}$ Department of Orthopaedics, Bone and Joints Hospital, Srinagar, India \\ *Corresponding author: Hayat Ahmad Khan, Department of Orthopaedics, Bone and Joints Hospital, Srinagar, India. Tel: +91-9906672626, Fax: +91-1942423389, E-mail: drhayatkhan@ \\ gmail.com
}

Received: October 20, 2014; Accepted: October 29, 2014

Keywords:Face; Epidemiology; Bone

\section{Dear Editor,}

We read with interest the Editorial published recently, entitled "The transforming face of fracture epidemiology" (1). The author has rightly pointed out the facts regarding the nonfatal patterns of skeletal fractures, which include the fractures induced by the restraint system like air bags and frontal motor vehicle collisions $(2,3)$. The various modification in designing of such light motor vehicles is needed to save people from catastrophic events. An input from the trauma centers to these manufacturers can help them in properly designing these motor vehicles. A general campaign among the masses can send a good message to the concerned people. Regarding the second part, children and women are more active than before and are now participating in high-energy recreational and athletic activities. This might be partly influenced by the social factors as well. Children usually indulge in indoor games and are often unattended during play hours (4). Osteoporosis is one of the global burdens in the state economy $(5,6)$. Proper screening by bone mineral density scan and proper management thereafter can decrease the fracture rate. A coordinated approach is needed to plan a proper strategy for the wellbeing of nation. Having an orthopedic trauma registry can show the actual burden of trauma. Then a plan can be made to prevent or decrease these events.

\section{References}

1. Haghpanah B. The Transforming Face of Fracture Epidemiology. Arch Trauma Res. 2014;3(3).

2. Blacksin MF. Patterns of fracture after air bag deployment. J Trauma.1993;35(6):840-3.

3. Estrada LS, Alonso JE, McGwin GJ, Metzger J, Rue L3. Restraint use and lower extremity fractures in frontal motor vehicle collisions. JTrauma. 2004;57(2):323-8.

4. Khan HA, Kamal Y, Shah AB, ul Gani N, Farooq M, Khan MA. Upholstered Bed Injuries among the Paediatric Population. Are We Concerned? An Institutional Experience. Int J Health Sci Res. 2014;4(10):47-51.

5. Cauley JA, Wampler NS, Barnhart JM, Wu L, Allison M, Chen Z, et al. Incidence of fractures compared to cardiovascular disease and breast cancer: the Women's Health Initiative Observational Study. Osteoporos Int. 2008;19(12):1717-23.

6. Maharlouei N, Khodayari M, Forouzan F, Rezaianzadeh A, Lankarani KB. The incidence rate of hip fracture in Shiraz, Iran during 2008-2010. Arch Osteoporos. 2014;9:165. 